\title{
Integration sites of human papillomavirus 18 in esophageal cancer samples
}

\author{
SHUYING LI ${ }^{1 *}$, ZHANJUN LIU $^{1}$, JIANGHONG YAN ${ }^{1}$, SHANGBO SUN $^{1}$, \\ XIAOLI HOU ${ }^{1}$, DIANQING LIU ${ }^{1}, \mathrm{KE} \mathrm{ZHANG}^{1^{*}}$ and JIN-TAO LI ${ }^{2 *}$ \\ ${ }^{1}$ School of Basic Medical Sciences, North China University of Science and Technology, Tangshan, Hebei 063000; \\ ${ }^{2}$ College of Life Science and Bioengineering, Beijing University of Technology, Beijing 100124, P.R. China
}

Received April 26, 2016; Accepted July 27, 2017

DOI: $10.3892 / \mathrm{ol} .2018 .8191$

\begin{abstract}
To investigate the association between human papillomavirus (HPV) infection and esophageal cancer, genomic DNA was isolated from 189 samples obtained from patients with esophageal carcinoma, and HPV DNA was identified using the polymerase chain reaction (PCR) with the following specific primers: My09/11 for HPV L1 and HPV18 E6 for HPV18. The HPV18 gene products were sequenced to identify the HPV genotype and the HPV18 integration site was verified using PCR amplification of papillomavirus oncogene transcripts. HPV18 oncogene transcript products were ligated into a pMD-18T plasmid vector and sequenced to confirm the physical location of HPV18 integration. Of the 189 samples, 168 were positive for HPV, of which 33 were positive for HPV18. The sequencing analysis identified two HPV18 E6-positive samples containing one mutation and two samples containing two mutations in the viral DNA. In total $~ 600$ bp of the HPV18 oncogene transcript was detected in three esophageal cancer samples. Sequence analysis revealed that, in two patients, the HPV18 infection was integrated into human chromosome 5, whereas in the remaining sample the virus was integrated into human chromosome 2 . The high prevalence of HPV18 infection suggested that HPV18 infection is a pathogenic factor in esophageal carcinoma progression. The integration of HPV18 DNA into the host cell genome suggests that persistent HPV
\end{abstract}

Correspondence to: Professor Ke Zhang, School of Basic Medical Sciences, North China University of Science and Technology, 57 Jianshe South Road, Tangshan, Hebei 063000, P.R. China E-mail: 877567295@qq.com

Dr Jin-Tao Li, College of Life Science and Bioengineering, Beijing University of Technology, 100 Pingleyuan, Chaoyang, Beijing 100124, P.R. China

E-mail: 511046476@qq.com

${ }^{*}$ Contributed equally

Key words: human papillomavirus, infection, integration, etiology, esophageal cancer infection has a role in esophageal epithelial cell malignant transformation and carcinogenesis.

\section{Introduction}

Esophageal carcinoma (EC) is the sixth most common type of cancer in China (1). Although the contributions of environmental factors, lifestyles and trace elements have been extensively investigated, the etiology of esophageal cancer has not yet been established (2-4).

In 1982, Syrjänen (5) first proposed that esophageal cancer is associated with HPV infection. Since then, numerous studies have supported this hypothesis (6-10).

In a previous study, HPV18 was detected and localized in human chromosome 8 in the esophageal squamous cell carcinoma EC109 cell line, which supported the hypothesis that HPV infection is a pathogenic factor in the development of esophageal cancer (11). Moreover, chronic high-risk HPV infection and the integration of elements of the viral genome into the human chromosome have proven to be pathogenic factors for cervical malignant transformation and lesions $(12,13)$.

Integrated and episomal HPV may be distinguished by amplifying papillomavirus oncogene transcripts (APOT) using the polymerase chain reaction (PCR), and Klaes et al (14) proposed that the location of HPV genome implantation in the human chromosome is an appropriate molecular tag for pathological lesions and the development of cancer. Nevertheless, few reports (11-14) have described the HPV integration site. The objective of the present study was to assess HPV18 infection and its location in the human genome in the setting of EC.

\section{Materials and methods}

Sample collection. Fresh surgically resected tissue samples from 189 patients who were pathologically diagnosed with esophageal carcinoma were obtained between March 2013 and December 2015; written informed consent was obtained from each specimen donor. All specimen donors were treated in the Pathology Department of Tangshan People's Hospital (Hebei, China); all patients came from the Tangshan area. The mean age was 58 years (range, 40-76 years), of which 136 were male and 53 female. All samples were esophageal 
squamous cell carcinoma, of which 30 were well differentiated, 104 were moderately differentiated and 55 were poorly differentiated. The samples were separated into 98 early-stage, 63 middle-stage and 28 late-stage specimens, according to the sixth and seventh editions of International Union Against Cancer classification (15); all fresh samples were stored at $-80^{\circ} \mathrm{C}$ prior to the experiments.

Cells and materials. The following media were used in the present study: Dulbecco's modified Eagle medium (DMEM) with antibiotics $(100 \mathrm{U} / \mathrm{ml}$ penicillin/streptomycin), fetal bovine serum, trypsin, and these reagents were provided by BioTek China, Beijing, China. QIAamp DNA Mini kit, Qiagen RNeasy Mini kit and Qiaquick Gel Extraction kit were provided by Qiagen GmbH, Hilden, Germany. Takara Ex Taq kit (including buffer, $\mathrm{MgCl}_{2}$, dNTPs, Taq DNA polymerase) was provided by Takara Bio, Inc., Otsu, Japan. The 293 cell line obtained from National Institute for Viral Disease Control and Prevention, Chinese Center for Disease Control and Prevention (Beijing, China).

Cell culture conditions. The 293 cell line were cultivated using $10 \mathrm{ml}$ media (DMEM with $100 \mathrm{U} / \mathrm{ml}$ penicillin-Streptomycin and $10 \%$ fetal bovine serum) in a $10 \mathrm{~cm}$ petri dish and maintained at $37^{\circ} \mathrm{C}$ in humidified atmosphere, containing $5 \%$ $\mathrm{CO}_{2}$ /and $95 \%$ air. Cell media were changed every 2-3 days.

Cell collection and DNA extraction. The 293 cells were washed twice using phosphate buffer saline (PBS) when the 293 cells were allowed to reach $90 \%$ confluence. Subsequently, cells were digested using $2 \mathrm{ml} 0.25 \%$ trypsin (including $0.02 \%$ EDTA), which was terminated using $2 \mathrm{ml}$ fresh cell medium, and transferred to $10 \mathrm{ml}$ flasks. Cells were centrifuged at $3,000 \mathrm{x} \mathrm{g}$ for $5 \mathrm{~min}$ at $4^{\circ} \mathrm{C}$ and the supernatant was removed. DNA extraction was performed using QIAamp DNA Mini kit, according to the manufacturer's protocol.

Plasmid. The plasmid HPV18/pBR322 (National Institute for Viral Disease Control and Prevention, Chinese Center for Disease Control and Prevention, China) DNA, containing the whole HPV18 genome, and DNA from the 293 cell line were stored at $-20^{\circ} \mathrm{C}$.

DNA extraction. DNA was extracted from each tissue specimen ( $25 \mathrm{mg})$ using the QIAamp DNA Mini kit according to the manufacturer's protocol, and each sample was eluted with $\sim 50 \mu 1$ sterilized distilled water. The extracted DNA was stored at $-20^{\circ} \mathrm{C}$ until further processing.

Detection of specimen quality and HPV DNA. The quality of the DNA from each tissue sample was assessed using PCR with $\beta$-actin primers (16). DNA from the 293 cell line was used as a control to ensure specimen quality.

HPV DNA for each specimen was analyzed by PCR using the primers My09/11 for HPV L1 (My09, 5'-CGTCCMARR GGAWACTGATC-3'; MY11, 5'-GCMCAGGGWCATAAY AATGG-3', PCR product 450 bp) (17) and HPV18 E6-specific primers (forward, 5'-GCGCTTTGAGGATCCAACAC-3' and reverse, 5'-ATTCAACGGTTTCTGGCAC-3'; the PCR product generated was $\sim 335 \mathrm{bp}$ ). The HPV18 E6 primers were designed on the basis of the genomic sequence of HPV18 in GenBank (accession number X05015.1).

Each PCR amplification was performed in a volume of $25 \mu \mathrm{l}$, containing $1 \mathrm{X}$ Ex Buffer $\left(\mathrm{MgCl}_{2}\right.$-free $), 2.5 \mathrm{mM} \mathrm{MgCl}_{2}$, $0.2 \mathrm{mM}$ dNTPs, $1 \mathrm{U}$ Ex Taq DNA polymerase, and 5 pmol each of the aforementioned forward and reverse primers. A total of $100 \mathrm{ng}$ extracted DNA template and control DNA were added to the reaction mixture. The following thermal cycling profile was employed: $95^{\circ} \mathrm{C}$ for $5 \mathrm{~min}$, followed by 31 cycles of $95^{\circ} \mathrm{C}$ for $30 \mathrm{sec}, 55^{\circ} \mathrm{C}$ for $30 \mathrm{sec}$ and $72^{\circ} \mathrm{C}$ for $30 \mathrm{sec}$. The last cycle was followed by a final extension step of $5 \mathrm{~min}$ at $72^{\circ} \mathrm{C}$.

Sequence analysis products of type-specific HPV18. To confirm the specificity of the HPV18 primers, the HPV18 E6-positive PCR products were purified using a Qiaquick Ge 1 Extraction kit according to the manufacturer's protocol. The products were then ligated into the $\mathrm{pMD}-18 \mathrm{~T}$ vector prior to being subjected to sequence analysis by Beijing Rui Bo Xing ke Biological Technology company using DNAman software v6.0 (www.shinegene.org.cn/q2.html).

Reverse transcription (RT). Total RNA was extracted from each sample using a Qiagen RNeasy Mini kit according to the manufacturer's protocol. RT was performed in a total volume of $25 \mu \mathrm{l}$ consisting of $4 \mu \mathrm{l} 5 \mathrm{X}$ first-strand buffer, $1 \mu \mathrm{l}$ dNTPs (0.2 mM), $1 \mu 1$ RNase inhibitor (40 U), $100 \mathrm{ng}$ total RNA, $1 \mu \mathrm{l}(\mathrm{dT})_{17} \mathrm{p} 3$ (10 pmol primer, GACTCGAGTCGACATCGA TTTTTTTTTTTTTTTTT), $1 \mu$ l SuperScript reverse transcriptase (200 U) and $9.2 \mu \mathrm{l}$ RNase-free water. The RNA was reverse-transcribed at $42^{\circ} \mathrm{C}$ for $50 \mathrm{~min}$ and deactivated at $70^{\circ} \mathrm{C}$ for $15 \mathrm{~min}$, and the resultant product was stored at $4^{\circ} \mathrm{C}$.

To verify that each tissue sample was harboring HPV with detectable HPV18 E7 mRNA, human GAPDH was employed as a reference gene for RT-PCR using the following primers: GAPDH forward, 5'-CATCACCATCTTCCAGGA-3' and reverse, 5'-GTCTACCACCCTATTGCA-3' (13). This approach guaranteed that the integrity of all mRNA extracted from each sample was sufficient for the detection of viral-cell fusion transcripts.

Detection of viral-cell fusion transcripts. The first PCR was prepared according to the method of Klaes et al (14), in a volume of $25 \mu \mathrm{l}$ using HPV18 E7-specific forward primers for p1-18 (5'-TAGAAAGCTCAGCAGACGACC-3') in HPV18 gene sequence $816 \ldots 836$ and reverse primers for p3 (5'-GAC TCGAGTCGACATCG-3'); the reaction system consisted of $1 \mathrm{X}$ Buffer, $10 \mathrm{pM}$ primers, $2.5 \mathrm{mM} \mathrm{MgCl}_{2}, 0.2 \mathrm{mM}$ dNTPs, $100 \mathrm{ng}$ cDNA product and $1 \mathrm{U}$ Ex Taq DNA polymerase. PCR was performed according to the following steps: $95^{\circ} \mathrm{C}$ for $5 \mathrm{~min}$, followed by 30 cycles at $95^{\circ} \mathrm{C}$ for $1 \mathrm{~min}, 56^{\circ} \mathrm{C}$ for $1 \mathrm{~min}$ and $72^{\circ} \mathrm{C}$ for $3 \mathrm{~min}$. The final cycle consisted of $72^{\circ} \mathrm{C}$ for $5 \mathrm{~min}$, and the sample was stored at $4^{\circ} \mathrm{C}$.

Nested PCR was performed under identical conditions (except for the annealing temperature, which was $67^{\circ} \mathrm{C}$ ) and the primers: the HPV18 E7-specific forward primer p2-18 (5'-ACGACCTTCGAGCATTCCAGCAG-3') in HPV18 gene sequence $831 \ldots 853$ and the reverse primer $(\mathrm{dT})_{17}$-p3; $5 \mu 1 \mathrm{PCR}$ product from the first round was used as the template. The two primers span bp 814-835 (p1-18) and bp 830-853 (p2-18) in the HPV18 genome. To ensure the specificity of these primers, a 
negative control (293 cell DNA template) was added to each reaction system.

Integration sites analysis. The HPV18 E7 PCR products for p2-18 were cloned into the pMD-18T vector. Subsequently, Beijing Rui Bo Xing ke Biological Technology sequenced. The results were blasted using the National Center for Biotechnology Information (blast.ncbi.nlm.nih.gov/Blast. cgi?PROGRAM=blastn\&PAGE_TYPE=BlastSearch\&LINK_ LOC=blasthome), HPV18 integration sites in human chromosome were determined for every specimen.

\section{Results}

Detection of specimen quality and HPV DNA. $\beta$-actin expression in a total of 189 samples was investigated to evaluate the DNA quality of the tissue specimens. A 290-bp $\beta$-actin product was detected in each sample. This result suggested that the DNA from each specimen was of high quality and satisfied the requirements for further experiments. Of the 189 specimens, 168 were positive for HPV DNA, as assessed using MY09/11 primers (Fig. 1A); 33 of these specimens were positive for HPV18 (Fig. 1B), assessed using the HPV18 E6-specific primers.

Sequence analysis for type-specific HPV18 products. The sequencing results of samples positive for HPV18 were analyzed with the DNA man software and compared with the HPV18 sequence provided in GenBank (X05015.1). The results of this analysis verified that four of the HPV18 E6-positive samples harbored mutations in the viral DNA: Two samples contained one mutation; the other two contained two mutations (Fig. 2).

HPV18 integration-derived transcripts in HPV18 E6-positive esophageal cancer samples. HPV18 integration sites were identified in all HPV18 E6-positive specimens. A 600 bp HPV18 E7 PCR product was identified in three samples using p2-18 primers. The HPV18 E7 PCR product obtained (using primer $\mathrm{p} 2-18$ ) from the three samples was ligated into the pMD-18T vector, and sequence analysis of the HPV18 integration sites was performed. The results of this sequencing analysis indicated that the HPV18 E7 gene PCR product, amplified using the p2-18 primer in these three samples, was part of the HPV18 E7-E1 sequence (Fig. 3A-C). Other sequences from two samples were similar to sequences from human chromosome 5 (Fig. 4A and B) and human chromosome 2 (Fig. 4C).

\section{Discussion}

The HPV positivity rate of $168 / 189$ observed in the present study is atypically high, comparing with previous studies in esophageal cancer $(10,18)$. This result indicated that the prevalence of HPV infection for esophageal cancer in the Tangshan area, and, taken in combination with previous studies (6-10), evidence indicates HPV may serve an etiological role in esophageal cancer. A total of $17.5 \%$ of 189 samples were positive for HPV18. The sequence analysis of PCR products positive for HPV18 E6 DNA identified two
A

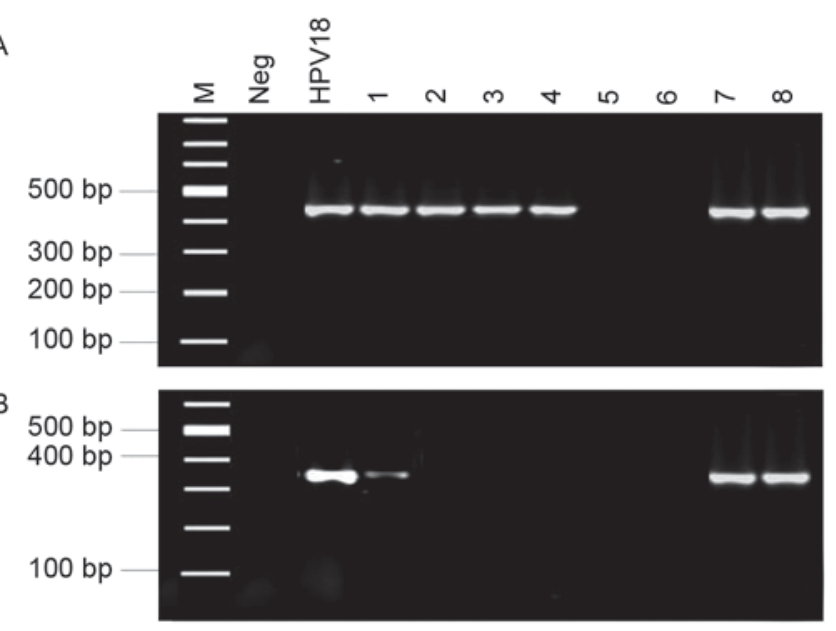

Figure 1. Detection of HPV DNA using primer pairs in esophageal carcinoma samples. (A) Detection of HPV DNA using primer pairs MY09/11 in esophageal carcinoma samples. (B) Detection of HPV18 DNA using primer pairs HPV18E6 in esophageal carcinoma samples. HPV, human papillomavirus; M, marker lane; Neg, negative control (template of 293 cell line DNA); HPV18, positive control using plasmid DNA of HPV18/pBR322 as a template; 1-8, results of HPV18 DNA detection from different esophageal cancer tissue DNA.

samples with one mutation in the viral DNA and two samples with two mutations. The results indicated that the samples harbored HPV18, and the high rates of HPV18 infection indicated that HPV18 has an etiological role in the development of esophageal carcinoma. Only part of HPV genome integrates into the human genome, and the HPV genome is usually cleaved at gene E1 or E2 $(14,19,20)$. The integration of HPV DNA, including the E6 and E7 genes, into the human genome generally includes the $5^{\prime}$ ends of the viral gene and the $3^{\prime}$ ends of the human cell sequences $(14,19,21,22)$. Viral-host cell-gene interconnection resulting from HPV DNA integration mediates DNA replication and recombination, with HPV E6 and E7 oncogene amplification being involved in tumorigenesis (23). HPV integration sites may be used as individualized biomarkers for cancer tumorigenesis (24). Chronic HPV infection results in the integration of the viral genome, which alters the expression patterns of viral oncogenes and integration-associated host-cell genes; this integration may have a vital function in the progression of cervical damage and cancer tumorigenesis (25).

Applying APOT analysis to 33 HPV18-positive samples, of which three HPV18-positive samples of integration-derived transcripts were: Two cases of late-stage, poorly differentiated cancer in men (aged 49 and 57 years); one case of early-stage moderately differentiated cancer in a woman (aged 71 years). Three patient samples is too few to be able to indicate that HPV18 integration is associated with sex, age, degree of differentiation or pathological stage of esophageal carcinoma, supporting the hypothesis that HPV-infected cells undergo preferred selective outgrowth in pre-neoplastic lesions that express the human-genome-integrated viral oncogenes E6 and E7. HPV18 integration was identified in esophageal cancer cells from three patient specimens, integrating into chromosomes 2 and 5. Taken together with the integration of HPV into the genome of EC109 cells, these results indicated that HPV randomly integrates into the host 


\begin{tabular}{|c|c|c|}
\hline ab1' & (1) & I \\
\hline '2. ab1' & (1) & CTTACAGAGGTATTTGAATTTGCATTTAAAGATTTATTTGTGGTGTATAGAGACAGTATACCGCATGCTGCATGCCATAAATGTATAGATTTTTAT \\
\hline '3. ab1' & (1) & ACTTACAGAGGTATTTGAATTTGCATTTAAAGATTTATTTGTGGTGTATAGAGACAGTATACCGCATGCTGCATGCCATAAATGTATAGATTTTTAT \\
\hline '4. ab1' & (1) & ACTTACAGAGGTATTTGAATTTGCATTTAAAGATTTATTTGTGGTGTATAGAGACAGTATACCGECATGCTGCATGCCATAAATGTATAGATTTT] \\
\hline 5015_1. SEQ' & (1) & ACTTACAGAGGTATTTGAATTTGCATTTAAAGATTTATTTGTGGTGTATAGAGACAGTATACCCCATGCTGCATGCCATAAATGTATAGATTTTT \\
\hline Consensus & (1) & CTTACAGAGGTATTTGAATTTGCATTTAAAGATTTATTT \\
\hline & & 101 \\
\hline '1. ab1' & (101) & AGAATTAGAGAATTAAGACATTATTCAGACTCTGTGTATG \\
\hline '2. ab1' & (101) & AGAATTAGAGAATTAAGACATTATTCAGACTCTGTGTATGGAGACACATTGGAAAAACTAAC \\
\hline '3. ab1' & (101) & AGAATTAGAGAATTAAGACATTATTCAGACTCTGTGTATGGAGACACATTGGAAAAACTAAC \\
\hline '4. ab1' & (101) & AGAATTAGAGAATTAAGACATTATTCAGACTCTGTGTATGGAGACACATTGGAAAAACTAAC \\
\hline 015_1. SEQ' & (101) & AGAATTAGAGAATTAAGACATTATTCAGACTCTGTGTATGGAGACACATTGGAAAAACTAACT \\
\hline & & \\
\hline
\end{tabular}

Figure 2. HPV18 sequencing results. 1.ab1'-'4.ab1, represents sequencing results of HPV18 E6 in four esophageal carcinoma specimens, with certain mutations compared with HPV18 E6 gene sequence in GenBank (X05015.1).

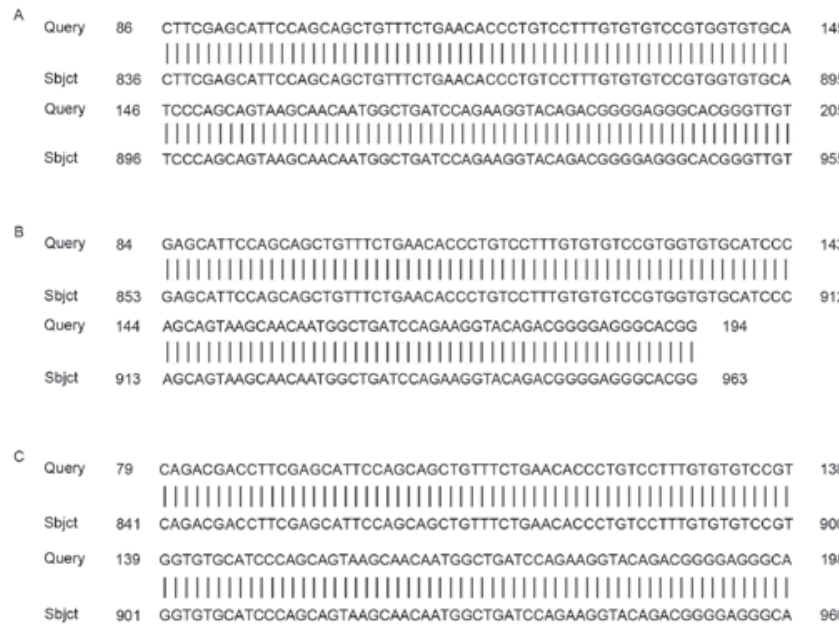

Figure 3. Alignment sequencing results compared with the sequence of HPV18. (A-C) Alignment of sequencing results of three esophageal carcinoma specimens compared with the HPV18 sequence. Query, sequence of three esophageal carcinoma specimens following PCR amplification with p2-18 E7-specific primers; Sbjct, corresponding part sequence of HPV18 E7-E1 in GenBank (X05015.1).

cell and that the HPV viral genome was cleaved at the E1 and $\mathrm{E} 2$ open reading frames prior to integration. The E2 gene serves as a pivotal modulator for E6 and E7 gene expression in the viral life cycle $(26,27)$. In a great proportion of HPV-infected patients, HPV E2 restrains E6 and E7 gene transcription, which aids the regulation of cellular proliferation (28). Cleavage of the E2 gene increased HPV E6 and E7 gene expression, which disrupts the cell cycle and leads to aberrant cellular proliferation (29-31). The HPV E6 and E7 genes usually integrate into the host cell genome and require longer incubation periods for the viral DNA replication and recombination to produce a variety of genetic changes in the viral and human genome $(32,33)$. The expression levels of E6 and E7 simultaneously increase, which results in human chromosomal instability and the development of malignant tumors (34).

The high prevalence of HPV18 infection suggested that HPV18 infection is a pathogenic factor for esophageal

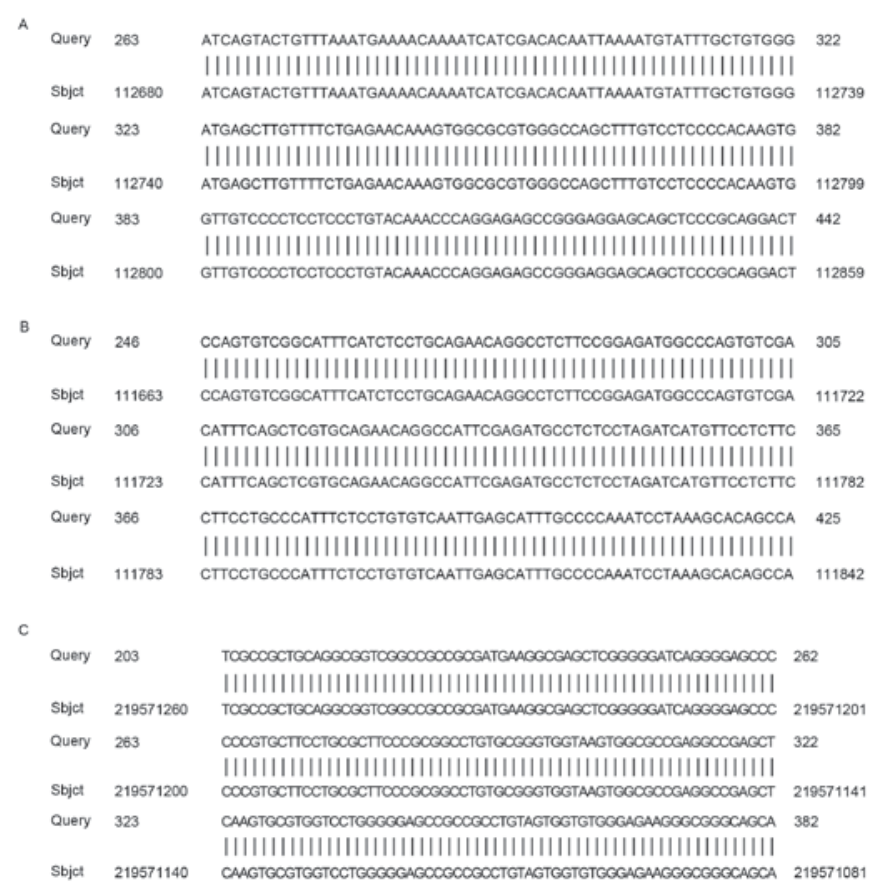

Figure 4. Alignment sequencing results compared with the human chromosome. (A-C) Alignment sequencing results of three esophageal carcinoma specimens compared with human chromosome. Query, sequencing results of three esophageal carcinoma specimens following PCR amplification with p2-18 E7-specific primers; Sbjct, part sequence of human chromosome.

carcinoma progression. The integration of HPV18 DNA into the host cell genome suggests that persistent HPV infection has a function in esophageal epithelial cell malignant transformation and carcinogenesis.

\section{Acknowledgements}

The present study was supported by the Project of Science and Technology for Overseas Scholars in Hebei Province (grant no. C201400559), the Project of North China University Science and Technology (grant no. SP201506), the Hebei Education Department (grant no. ZD2016003), and Beijing Natural Science Foundation (grant no. 5162003). 


\section{Competing interests}

The authors declare that they have no competing interests.

\section{References}

1. Zhao J, He YT, Zheng RS, Zhang SW and Chen WQ: Analysis of esophageal cancer time trends in China, 1989-2008. Asian Pac J Cancer Prev 13: 4613-4617, 2012.

2. Sun X, Chen W, Chen Z, Wen D, Zhao D and He Y: Population-based casecontrol study on risk factors for esophageal cancer in five high-risk areas in China. Asian Pac J Cancer Prev 11: 1631-1636, 2010.

3. Zhang HZ, Jin GF and Shen HB: Epidemiologic differences in esophageal cancer between Asian and Western populations. Chin J Cancer 31: 281-286, 2012.

4. Esophageal cancer: Epidemiology, pathogenesis and prevention. Nat Clin Pract Gastroenterol Hepatol 5: 517-526, 2008.

5. Syrjänen KJ: Histological changes identical to those of condylomatous lesions found in esophageal squamous cell carcinomas Arch Geschwulstforsch 52: 283-292, 1982.

6. Dong HC, Cui XB, Wang LH, Li M, Shen YY, Zhu JB, Li CF, Hu JM, Li SG, Yang L, et al: Type-specific detection of human papillomaviruses in Kazakh esophageal squamous cell carcinoma by genotyping both E6 and L1 genes with MALDI-TOF mass spectrometry. Int J Clin Exp Pathol 8: 13156-13165, 2015.

7. Türkay DÖ, Vural Ç, Sayan M and Gürbüz Y: Detection of human papillomavirus in esophageal and gastroesophageal junction tumors: A retrospective study by real-time polymerase chain reaction in an instutional experience from Turkey and review of literature. Pathol Res Pract 212: 77-82, 2016.

8. Ludmir EB, Stephens SJ, Palta M, Willett CG and Czito BG: Human papillomavirus tumor infection in esophageal squamous cell carcinoma. J Gastrointest Oncol 6: 287-295, 2015.

9. Georgantis G, Syrakos T, Agorastos T, Miliaras S, Gagalis A, Tsoulfas G, Spanos K and Marakis G: Detection of human papillomavirus DNA in esophageal carcinoma in Greece. World J Gastroenterol 21: 2352-2357, 2015.

10. Liu HY, Zhou SL, Ku JW, Zhang DY, Li B, Han XN, Fan ZM, Cui JL, Lin HL, Guo ET, et al: Prevalence of human papillomavirus infection in esophageal and cervical cancers in the high incidence area for the two diseases from 2007 to 2009 in Linzhou of Henan Province, Northern China. Arch Virol 159: 1393-1401, 2014.

11. Zhang K, Li JT, Li SY, Zhu LH, Zhou L and Zeng Y: Integration of human papillomavirus 18 DNA in esophageal carcinoma 109 cells. World J Gastroenterol 17: 4242-4246, 2011.

12. Zhang R, Shen C, Zhao L, Wang J, McCrae M, Chen X and Lu F: Dysregulation of host cellular genes targeted by human papillomavirus (HPV) integration contributes to HPV-related cervical carcinogenesis. Int J Cancer 138: 1163-1174, 2016.

13. Xu F, Cao M, Shi Q, Chen H, Wang Y and Li X: Integration of the full-length HPV16 genome in cervical cancer and Caski and Siha cell lines and the possible ways of HPV integration. Virus Genes 50: 210-220, 2015.

14. Klaes R, Woerner SM, Ridder R, Wentzensen N, Duerst M, Schneider A, Lotz B, Melsheimer P and von Knebel Doeberitz M: Detection of high-risk cervical intraepithelial neoplasia and cervical cancer by amplification of transcripts derived from integrated papillomavirus oncogenes. Cancer Res 59: 6132-6136, 1999.

15. Reeh M, Nentwich MF, von Loga K, Schade J, Uzunoglu FG, Koenig AM, Bockhorn M, Rosch T, Izbicki JR and Bogoevski D: An attempt at validation of the Seventh edition of the classification by the International UnionAgainst Cancer for esophageal carcinoma. Ann Thorac Surg 93: 890-896, 2012.
16. Lee DC, Cheung CY, Law AH, Mok CK, Peiris M and Lau AS: p38 mitogen- activated protein kinase-dependent hyperinduction of tumor necrosis factor alpha expression in response to avian influenza virus H5N1. J Virol 79: 10147-10154, 2005.

17. Karlsen F, Kalantari M, Jenkins A, Pettersen E, Kristensen G, Holm R, Johansson B and Hagmar B: Use of multiple PCR sets for optimal detection of human papillomavirus. J Clin Microbiol 34: 2095-2100, 1996.

18. Syrjänen KJ: HPV infections and oesophageal cancer. J Clin Pathol 55: 721-728, 2002.

19. Kadaja M, Sumerina A, Verst T, Ojarand M, Ustav E and Ustav M: Genomic instability of the host cell induced by the human papillomavirus replication machinery. EMBO J 26: 2180-2191, 2007.

20. Johansson C, Somberg M, Li X, Backström Winquist E, Fay J, Ryan F, Pim D, Banks L and Schwartz S: HPV-16 E2 contributes to induction of HPV-16 late gene expression by inhibiting early polyadenylation. EMBO J 31: 3212-3227, 2012.

21. Venuti A and Marcante ML: Presence of human papillomavirus type 18 DNA in vulvar carcinomas and its integration into the cell genome. J Gen Virol 70: 1587-1592, 1989.

22. Klimov E, Vinokourova S, Moisjak E, Rakhmanaliev E, Kobseva V, Laimins L, Kisseljov F and Sulimova G: Human papilloma viruses and cervical tumours: Mapping of integration sites and analysis of adjacent cell ularsequences. BMC Cancer 2: $24,2002$.

23. Akagi K, Li J, Broutian TR, Padilla-Nash H, Xiao W, Jiang B, Rocco JW, Teknos TN, Kumar B, Wangsa D, et al: Genome-wide analysis of HPV integration in human cancers reveals recurrent, focal genomic instability. Genome Res 24: 185-199, 2014.

24. Xu B, Chotewutmontri S, Wolf S, Klos U, Schmitz M, Dürst M and Schwarz E: Multiplex identification of human papillomavirus 16 DNA integration sites in cervical carcinomas. PLoS One 8: e66693, 2013.

25. Lu X, Lin Q, Lin M, Duan P, Ye L, Chen J, Chen X, Zhang L and Xue X: Multiple-integrations of HPV16 genome and altered transcription of viral oncogenes and cellular genes are associated with the development of cervical cancer. PLoS One 9: e97588, 2014.

26. Steger G and Corbach S: Dose-dependent regulation of the early promoter of human papillomavirus type 18 by the viral E2 protein. J Virol 71: 50-58, 1997.

27. Nishimura A, Ono T, Ishimoto A, Dowhanick JJ, Frizzell MA, Howley PM and Sakai H: Mechanisms of human papillomavirus E2-mediated repression of viral oncogene expression and cervical cancer cell growth inhibition. J Virol 74: 3752-3760, 2000.

28. Wells SI, Aronow BJ, Wise TM, Williams SS, Couget JA and Howley PM: Transcriptome signature of irreversible senescence in human papillomavirus-positive cervical cancer cells. Proc Natl Acad Sci USA 100: 7093-7098, 2003.

29. Bergner S, Halec G, Schmitt M, Aubin F, Alonso A and Auvinen E: Individual and complementary effects of human papillomavirus oncogenes on epithelial cell proliferation and differentiation. Cells Tissues Organs 201: 97-108, 2016.

30. Ekalaksananan T, Jungpol W, Prasitthimay C, Wongjampa W, Kongyingyoes B and Pientong C: Polymorphisms and functional analysis of the intact human papillomavirus16 e2 gene. Asian Pac J Cancer Prev 15: 10255-10262, 2014.

31. Scheffner M, Romanczuk H, Münger K, Huibregtse JM, Mietz JA and Howley PM: Functions of human papillomavirus proteins. Curr Top Microbiol Immunol 186: 83-99, 1994.

32. Alp Avc1 G: Genomic organization and proteins of human papillomavirus. Mikrobiyol Bul 46: 507-515, 2012 (In Turkish).

33. Kessis TD, Connolly DC, Hedrick L and Cho KR: Expression of HPV16 E6 or E7 increases integration of foreign DNA. Oncogene 13: 427-431, 1996.

34. Hillemanns P and Wang X: Integration of HPV-16 and HPV-18 DNA in vulvar intraepithelial neoplasia. Gynecol Oncol 100: 276-282, 2006 